\title{
Failure Investigation Report on Different Components of an Automotive Engine
}

\author{
Md. Raquibul Hasan \\ Department of Civil Engineering, Pabna University of Science \& Technology, Pabna, Bangladesh \\ Email address: \\ raquibul.hasan@pust.ac.bd
}

\section{To cite this article:}

Md. Raquibul Hasan. Failure Investigation Report on Different Components of an Automotive Engine. International Journal of Mechanical Engineering and Applications. Vol. 5, No. 1, 2017, pp. 47-51. doi: 10.11648/j.ijmea.20170501.16

Received: January 6, 2017; Accepted: February 8, 2017; Published: March 1, 2017

\begin{abstract}
This paper presents an investigation report of different components failure which affect the performance of an automobile engine. The premature breakage of a four cylinder diesel engine block, crankshaft, camshaft, crankshaft bearing, camshaft bush, engine oil pump was reported. It is found that the failure of each component having the same reason for its failure as reported from different place. Thus it affected the performance of the vehicle and it is very expensive for the customer to replace the damaged parts for several times. In this paper, we presented detailed analysis of the causes for the failure along with preventive suggestion to maintain the engine for better performance.
\end{abstract}

Keywords: Failure Analysis, Thermal Fatigue, Engine Block, Connecting Rod, Head Gasket

\section{Introduction}

Internal combustion (IC) engine is a complex power generating machines and used widely in automotive industry. Automotive component failure is a common phenomenon. It affects the life of every person at one stage or another. Automotive vehicles often operate under onerous condition and many of them last lifetime without any form of inspection. In many cases, if any parts of a vehicle damaged, it replaced without any further inspection. Thus, a sudden failure of any components may cause accidents, in which there will be loss of life. Normally, the owner of the automotive vehicle are not interested for the vehicles periodical maintenance and other inspections. Thus, a sudden failure of components may occur. There are many parts which are normally termed as the heart of a vehicle. If they got damaged there will be possibilities of accidents. Such kind of parts are known as safety critical items and a batch related in-service failure of such parts will often result in the recall of all affected vehicles with the associated cost and bad publicity. Thus in automotive failure analysis it is imperative to determine the root cause of failure whether it is likely to occur in more vehicles. Failures arise due to many reasons: mechanical stresses; thermal stresses; wear mechanisms; temperature degradation, oxidation mechanisms; etc. Although, traditionally, for automotive vehicles, engine component damages are attributed to wear and lubrication sources. And some damages where the main cause is attributed to wear and/or lubrication mechanisms may have in the root cause origin a fatigue crack.

Based on an analysis of seventy automotive component failures received for investigation. Failure rate is usually time dependent, and an intuitive corollary is that the rate changes over time versus the expected life cycle of a system. For example, as an automobile grows older, the failure rate in its fifth year of service may be many times greater than its failure rate during its first year of service-one simply does not expect to replace an exhaust pipe, overhaul the brakes, or have major transmission problems in a new vehicle. The distribution of component failure and the distribution of causes are given in Fig. 1 and 2 respectively. From this it can be seen that the most common component failure is that of the engine $(41 \%)$ and that the most common cause of failure is abuse $(29 \%)$ [1]

A company contributed the failure parts to investigate the failure phenomenon. This paper presents four summarized case studies of automotive component failures, with the aim of demonstrating the valuable information which can be gained by failure analysis. 


\subsection{Component Failure Distribution Chart}

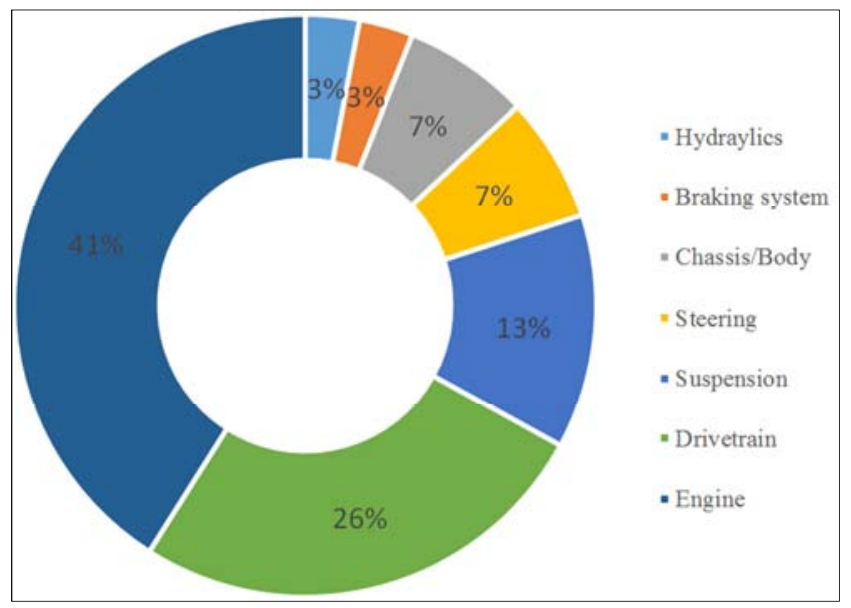

Figure 1. The distribution of component failures.

\subsection{Distribution of Cause Chart}

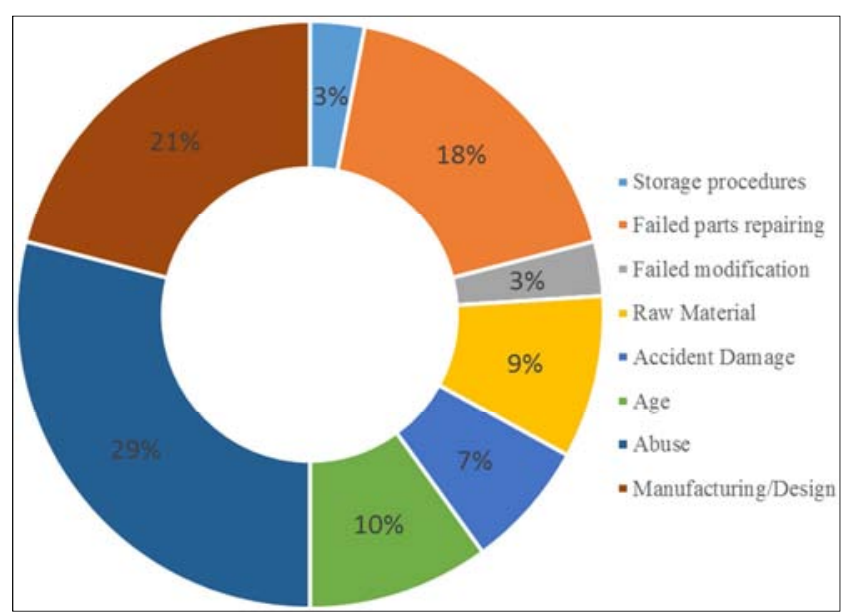

Figure 2. The distribution of causes of failure.

\section{Methodology}

The purpose of a failure investigation is to determine the root cause(s). Determination of root cause is good engineering practice that crosses functional boundaries within a company and is an integral part of the quality assurance and continuous improvement programs. A proper failure investigation is not a "science project." In addition, there is a distinct difference between a failure investigation and a metallurgical evaluation. A root-cause failure investigation determines the root cause of the failure and recommends appropriate corrective actions. In contrast, a metallurgical evaluation provides the answers to the metallurgical questions posed in the failure investigation. Therefore, a metallurgical evaluation is only one part of a failure investigation.

In this investigation

The following investigations was done step by step for the failure analysis.

- Improper maintenance and repair.
- Overloading and other service abuses.

- Design shortcomings.

- Material imperfections due to faulty processing or fabrication.

- Environment-material interactions.

To determine the cause of the failures, the following method was used:

- Appearance - an illustration and brief description of a component that has failed due to a specific cause.

- Damaging Action - what actually damaged the component under the conditions which were present?

- Possible Causes - a listing of those factors capable of creating the particular damaging action.

- Corrective Action - the action that should be taken to correct the cause of failure.

\section{Investigation of Different Component Failure of an Engine}

The engine of the vehicle we have selected for the failure analysis have the following specification in Table-1:

Table 1. Specification of the investigated engine.

\begin{tabular}{ll}
\hline Specification & \\
\hline Type & In-line, water-cooling, direct injection \\
\hline No of Cylinder & 4 \\
Cylinder Bore (mm) & 80 \\
Piston Stroke (mm) & 90 \\
Compression ratio & $18: 1$ \\
Displacement (L) & 1.809 \\
Cylinder working sequence & $1-3-4-2$ \\
Rated Speed (rpm) & $2200-3200$ \\
Rated power (kw) & $12-30$ \\
Max. torque (N.m) & 97 \\
Max. torque speed (rpm) & $1540-2240$ \\
Oil At idle speed & $\geq 50 \mathrm{kPa}$ \\
pressure At rated speed & $\geq 200-400 \mathrm{kPa}$ \\
\hline
\end{tabular}

As reported from different place the vehicle's engine is being getting damaged with a crack on the engine block and damage of other parts. A detailed inspection of this failure is presented in the following section of this paper.

\subsection{Hole in Block}

\subsubsection{Analysis of Causes}

Catastrophic bearing failure can be as a result of both isolated and progressive bearing wear and/or contamination. A progressive failure generally isolates the actual failure towards the end of the engines oil gallery flow, typically rear of the engine assembly.

This can be from both lack of sufficient oil volume and foreign dust, dirt or abrasives and/or metallic particles present in the oil supply. The foreign particles can embed in the soft Babbitt bearing lining displacing metal and creating a high spot as the material is re-plastered to additional bearing materials while the lack of oil volume will cause a wiping of the bearing surface leading to a "Hot-Short" condition. Evidence of either of these conditions will leave some degree 
of damage and wear throughout all bearing surfaces with "progressive" damage being exhibited as the oil flow travels through the engine creating more debris.

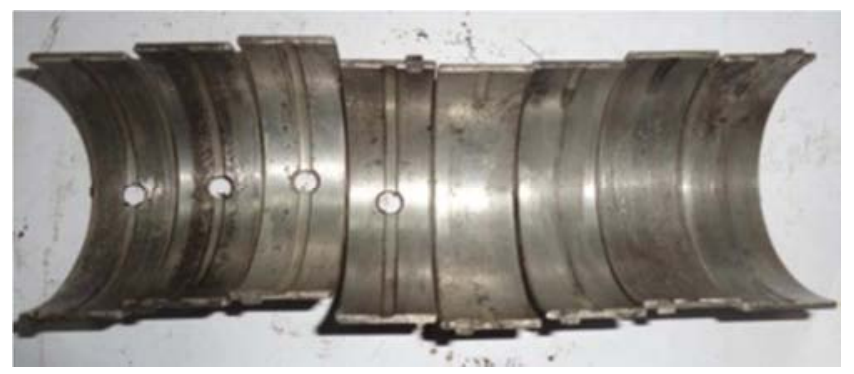

Figure 3. Damaged Crankshaft Bearing.

Catastrophic connecting rod failure can be as a result of incorrect clearances causing bearing failure, incorrect torque applied to the fasteners, engine over speeding resulting in hyper-articulation of the connecting rods and connecting rod bolt failure.

Incorrect clearances will result in seizure of the connecting rod bearing. Once started, through continued operation, the friction, debris and heat generated by the seizure of that bearing can cause the oil to vaporize and create a lack of lubrication condition commonly shared with its partner connecting rod in V8 applications sharing the same rod journal. The generated heat will remove the hardness from the crankshaft, leaving a blackened appearance. With the continued operation this can lead to the connecting rod to disengage from to crankshaft and collide with the rotating assembly. A series of high energy collisions can create a high degree of secondary damage to the engine assembly.

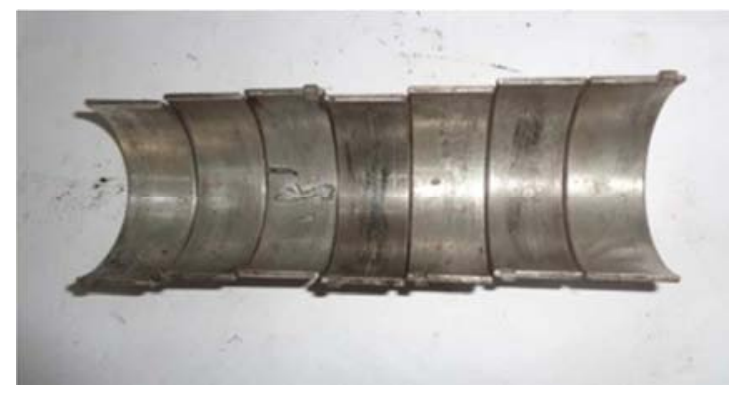

Figure 4. Damaged Connecting rod bearing.

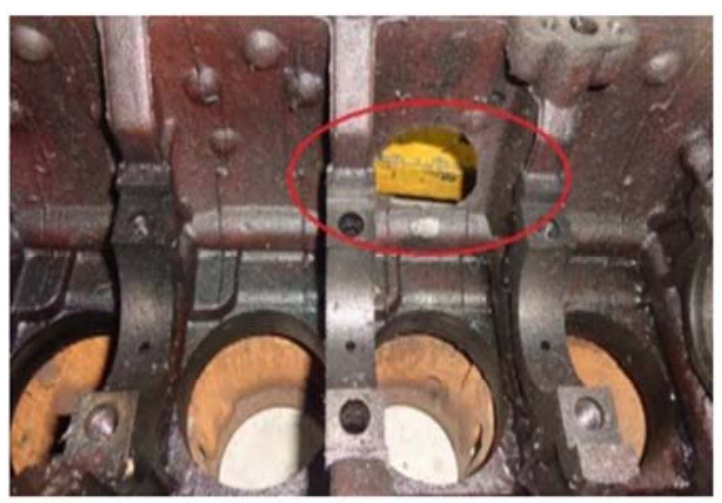

Incorrect torque applied to the fasteners can be observed typically by at least one if not both bolts still intact with collateral damage from a subsequent high energy collision within the engine assembly. As most connecting rod bolts require an engineered amount of "stretch" to maintain torque, once loose can work their way out of their threaded end within seconds. This leaves the bearing lacking any evidence of a lubrication or contaminant concern with the crankshaft journal still polished in appearance with only the subsequent collateral damage caused from the connecting rod disengaging from the crankshaft.

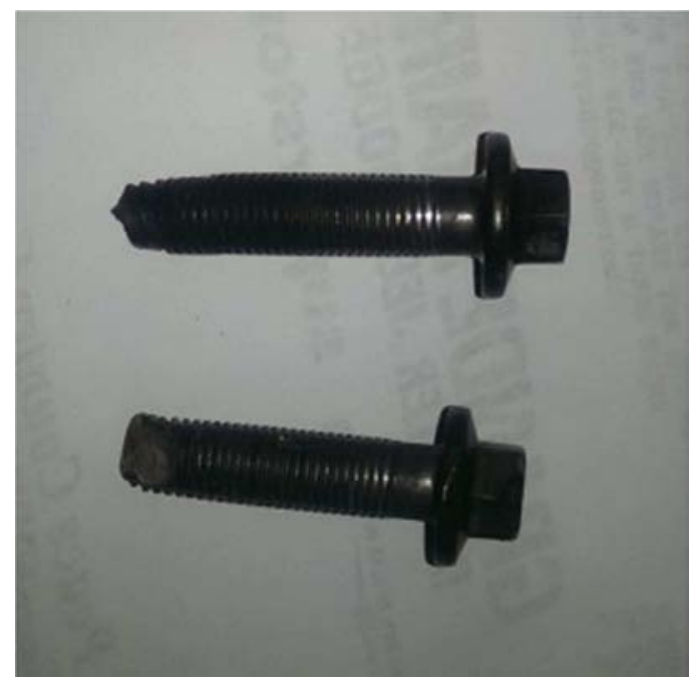

Figure 5. Damaged Connecting rod bolts.

Engine over speeding can be as a result of down shifting an automatic or manual transmission in too low of gear for the current vehicle speed, operating the engine at a higher than designed engine rpm from aftermarket tuning and sudden drivetrain failure on a loaded engine causing unregulated engine rpm gains through inertia. As this failure can happen suddenly it typically leaves the condition of a relatively undamaged bearing and crankshaft journal, excluding collateral damage from the resulting high energy collision, but leaves the threaded end of the connecting rod bolts in the upper connecting rod assembly. This is possible from the bolts achieving their tensile stress point and break at the mating surface where the cap meets the connecting rod.

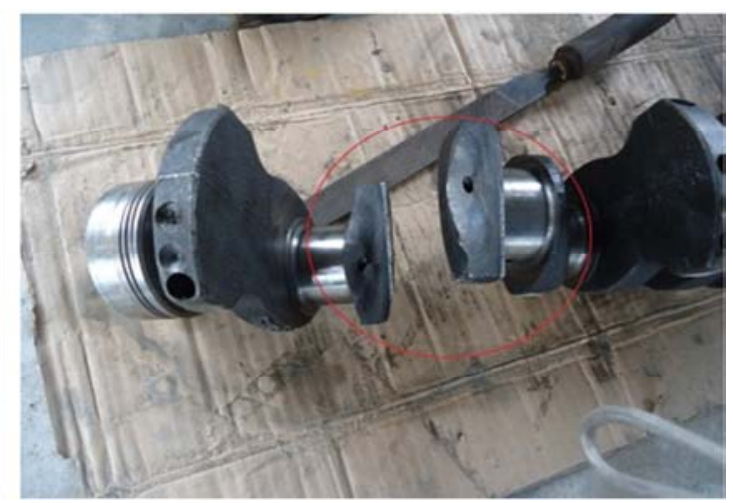

Figure 6. Cracked engine block and crankshaft. 
Connecting rod bolt failure generally leaves the condition of at least one bolt with the head broken off, the bolt split at an angle down its length and the opposing bolt broken off within the upper connecting rod half. This can result in a sudden catastrophic failure resulting in a high energy collision with the connecting rod, crankshaft and block assembly but will leave the crankshaft and bearing assembly with their previous polished appearance with only collateral damage from the collision being observed.

Failure of bearings and rods from contamination and/or oil flow issues are generally as a result of failure to replace an oil cooler from a previous engine failure, inadequate oil amount, missing oil gallery plugs, worn oil pump and blocked oil galleries. Incorrectly torqued fasteners will generally cause failure within the first few thousand kilometres/miles and failure as a result of engine over speeding typically shears both rod bolts off flush the machined or fractured connecting rod joint.

\subsubsection{Control Measure}

Engine coolant is what's supposed to keep the overall engine within operating temperature. Water pump should have to check whether there is a leak from the pump. Machine have to be improved in aspect of products forming and process technology. The crankshaft must be strong enough to take the downward thrusts of the pistons during the power strokes without excessive distortion. In most instances, replacing an engine with a cracked engine block is the best solution, particularly if the customer is interested in a salvage engine or a rebuilt engine (both of which are more economical than crate or remanufactured engines).

\subsection{Bent Connecting Rod}

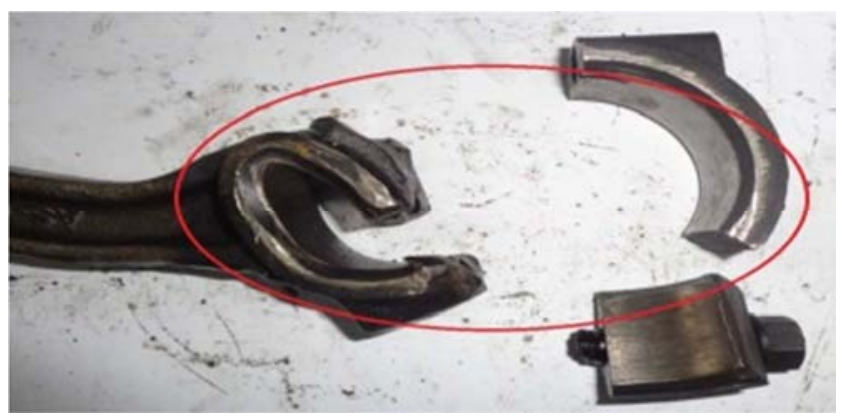

Figure 7. Bent Connecting rod.

\subsubsection{Analysis of Causes}

Hydrostatic lock occurs when a volume of liquid greater than the volume of the cylinder minimum (end of the pistons stroke) enters the cylinder. Since most common liquids are incompressible the piston cannot complete its travel; either the engine must stop rotating or a mechanical failure must occur. Diesel engines are more susceptible to hydro lock than gasoline engines. Due to their higher compression ratios, diesel engines have a much smaller final combustion chamber volume, requiring much less liquid to hydro lock. Diesel engines also have higher torque, rotating inertia and stronger starter motors than gasoline engines. The result is that a diesel engine is much more likely to suffer catastrophic damage from ingestion of incompressible fluids.

Typical causes of this concern is from ingestion of fluids through the intercooler, water in fuel and improper torqueing of injector hold down bolts.

\subsubsection{Control Measure}

As the hydrolock mainly occurs when driving through floods, either where the water is above the level of the air intake or the vehicle's speed is excessive. Excessive fuel entering (flooding) one or more cylinders in liquid form due to abnormal operating conditions can also cause hydrolock. Thus the customers should have to be advised for not run the vehicle through standing water or heavy precipitation. Always have intercooler and piping professionally cleaned when installing a new engine and follow the original equipment manufacturers recommended torque sequences. If a water in fuel light comes on vehicle should be towed, not driven to a dealer for further inspection.

\subsection{Cracked Piston}

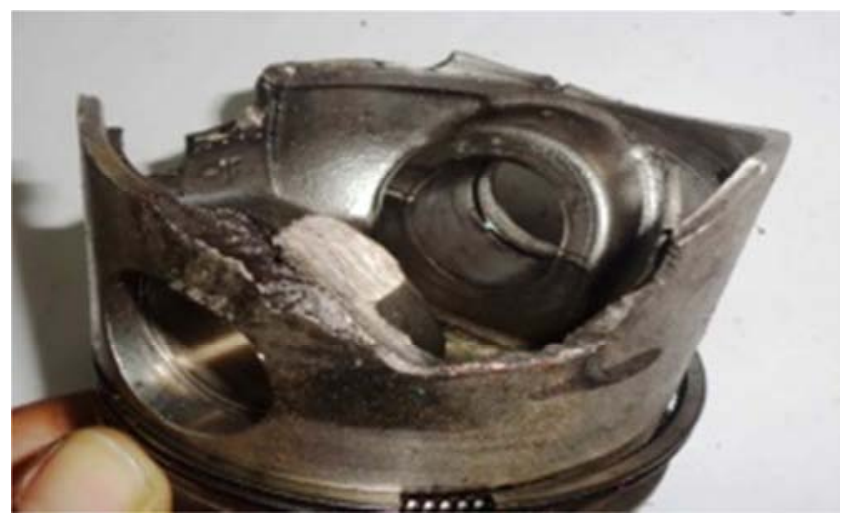

Figure 8. Cracked Piston.

\subsubsection{Analysis of Causes}

Cracking of the piston crown around the combustion bowl will display radial cracks at the bowl rim on direct injection diesel engines. This is caused from a premature or excessive fuel injection to cause high thermal and mechanical loads causing fatigue as the piston is bent around the wrist pin as it drives the piston through the compression stroke in the presence of excessively high cylinder pressurization and thermal stress. When this occurs the most heated part of the combustion chamber, surrounded by less heated regions, can't expand in accordance with its expansion coefficient at high temperature. Because the material cannot compress the only way is to expand in the direction of a free surface. A plastic deformation occurs from the accumulated material which once the piston cools, the deformation persists, resulting in tensile stresses which lead to cracks at the combustion chamber corners. The wedge effect in conjunction with the presence of quick changes in temperature fatigues the piston in this area causing the piston to fracture. 
Excessive high cylinder pressurization can be the result of malfunctioning fuel injection, advanced fuel injection timing or hydrostatic lock. To reduce the risk of this happening DFC can remove the lip in the combustion bowl helping to prevent radial cracks that can form from extreme thermal tensions.

Excessive high cylinder pressurization can be the result of malfunctioning fuel injection, advanced fuel injection timing or hydrostatic lock.

\subsubsection{Control Measure}

The EGR valve operation have to inspect for carbon buildup and clean as needed. Also the cylinder pressure have to check, as well as advanced fuel injection timing should inspect.

\subsection{Head Gasket Failure}

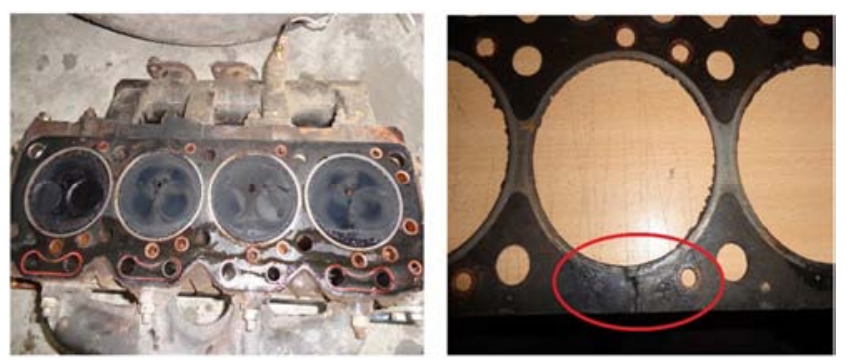

Figure 9. Cylinder head \& Head gasket.

\subsubsection{Analysis of Causes}

The root causes for many of these failures are unrelated to the sealing joint itself and cannot be detected by an examination of the cylinder head gaskets alone. Cylinder head gasket failures and other engine damage occurring in these engines have found to be directly linked to hydrostatic lock from injector and EGR cooler failures. Another very common root cause for cylinder head gasket failures in this engine are as a result of excessively high cylinder pressures through the utilization of aftermarket performance tuning programs. To produce a viable seal, the gasket relies on an even application of adequate amounts of clamping force. The excessively high cylinder pressures produced by aftermarket performance tuners and hydrostatic lock effectively lift the cylinder head off the cylinder block reducing clamp load applied to the gaskets, breaking the combustion seal and initiates leakage.

\subsubsection{Control Measure}

Extensive damage caused by a blown head gasket can be the most detrimental form of engine problems. If a faulty head gasket is not detected early, a required repair of the engine block, the cylinder head, or a complete engine replacement could be required. Coolant can leak into the combustion chamber and can cause abnormal smoke emissions. This issue alone, for example, could likely result in having to replace the catalytic converter.

\section{Conclusion}

From the survey of automotive component failure, it is found that failure occurs mainly from abuse and lack of maintenance, which are unavoidable. If the vehicle is maintained properly, there should be a substantial reduction of the failure. Some area must have to maintain from service point of view, these are- maintain proper ignition timing and valve timing. Timely change the engine oil, if vehicle not run up to specified $\mathrm{km}$ in that condition consider the time period which play very important role. Fixation of engine compartment with sufficient space especially backside of the engine for better heat dissipation space should be more. In condition of cold starting engine sudden acceleration must be avoided.

\section{References}

[1] A. M. Heyes, "Automotive Component Failures" Engineering Failure Analysis, Elsevier Science Ltd, Vol. 5, No. 2 pp. 129141, 1998.

[2] F. S. Silva, "Analysis of a vehicle crankshaft failure" Engineering Failure Analysis, Vol. 10, pp. 605-616, 2003.

[3] F. S. Silva, "Fatigue on engine pistons - A compendium of case studies" Engineering Failure Analysis, Vol. 13 pp. 480 492, 2006

[4] William H Crouse, Automotive Mechanics, Tenth Edition Tata McGraw Hill

[5] P. S Shenoy, A Fatemi "Dynamic Analysis Of Loads and Stresses in Connecting Rods", J. Mechanical Engineering Science, Vol. 220, pp. 615-624, 2006.

[6] A. R Bhagat, YM Jibhate, "Thermal Analysis \& Optimization Of IC Engine Piston using FEM" International Journal Of Modern Engineering Research, Vol. 2, Issue. 4, pp. 29192921,2010

[7] Sasi Prabhala, K. Sunil Ratna Kumar, "Design and Weight Optimization Of IC Engine", International Journal Of Advanced Engineering Research and Studies, Vol. 2, Issue. 1, pp. 56-58, 2012.

[8] Naresh Kr. Raghuwanshi, Failure Analysis of Internal Combustion Engine Valves: A Review, International Journal of Innovative Research in Science, Engineering and Technology, Vol. 1, Issue 2, December 2012.

[9] R. C. Singh, Failure of Piston in IC Engines: A Review, IJMER | ISSN: 2249 6645, Vol. 4, Iss. 9, Sept. 2014.

[10] Tanu Singhai, Analysis and Performance of Automobile Engine Components Considering Thermal and Structural Effects, International Journal of Innovative Research in Science, Engineering and Technology Vol. 3, Issue 1, January 2014. 